\title{
Pancreatic duct hyperplasia/dysplasia in type 1 diabetes and pancreatic weight in individuals with and without diabetes. Reply to Kobayashi T, Aida K, Fukui T et al [letter] and Saisho Y [letter]
}

\author{
Martha L. Campbell-Thompson ${ }^{1}$ • Desmond A. Schatz ${ }^{2}$ - John S. Kaddis ${ }^{3}$. \\ Mark A. Atkinson ${ }^{1}$
}

Received: 6 January 2016 / Accepted: 12 January 2016 / Published online: 9 February 2016

(C) Springer-Verlag Berlin Heidelberg 2016

Keywords Chronic pancreatitis · Ductal hyperplasia $\cdot$ GAD autoantibodies $\cdot$ Heterogeneity $\cdot$ Insulitis $\cdot$ LADA $\cdot$ nPOD . PanIN $\cdot$ Relative pancreas weight $\cdot$ Type 2 diabetes

\begin{abstract}
Abbreviations
LADA Latent autoimmune diabetes in adults

nPOD Network for Pancreatic Organ donors with Diabetes

PanIN Pancreatic Intraepithelial Neoplasia
\end{abstract}

To the Editor: We thank the Editor for providing the opportunity to respond to comments made in a letter by Dr Kobayashi et al [1] regarding our recent short communication noting that relative pancreas weight ratios (ratio of pancreas weight to body weight) allows for comparison between children and adults with type 1 diabetes [2].

Kobayashi et al conclude from their own studies that patients with slowly progressive diabetes have reduced pancreas weight compared with those with the more acute onset form. Unfortunately, we were unable to document such a difference

Mark A. Atkinson

atkinson@ufl.edu

1 Department of Pathology, Immunology, and Laboratory Medicine, College of Medicine, University of Florida, POB 100275 , 1395 Center Drive, Gainesville, FL 32610, USA

2 Department of Pediatrics, College of Medicine, University of Florida, Gainesville, FL, USA

3 Department of Information Sciences, City of Hope, Duarte, CA, USA since there is great difficulty in distinguishing subtypes so many years post diagnosis. It is clear that there is marked heterogeneity in type 1 diabetes, with age, geographical, genetic and environmental factors likely representing important contributors $[3,4]$. What 'slowly progressive diabetes' represents outside the Japanese population remains the subject of debate. This subgroup had been given various names including 'type 1.5 diabetes', 'autoimmune diabetes in adults' and 'slow-onset diabetes in adults' even before the latent autoimmune diabetes in adults (LADA) acronym was coined to describe autoantibody-positive patients who were initially diagnosed with type 2 diabetes [5].

With this background of controversies and confusion with respect to diabetes classification terminologies, the natural question is one of how diabetes is defined in our investigational studies. In this work, patients are classified by a boardcertified endocrinologist (D. Schatz) based on chart records, as well as standard clinical (ADA) criteria and evaluation of laboratory studies including islet autoantibodies, HLA and Cpeptide levels prior to histopathological studies [6]. Consistent with the field, no unified criteria are reported for LADA, although three factors are commonly considered: positivity for GAD autoantibodies (GADA), age $>35$ years at onset and non-insulin therapy in the first 12 months after diagnosis [5].

Although Kobayashi et al reported that those identified as having LADA had significantly reduced pancreas weights compared with patients with acute type 1 diabetes $(29.8 \pm 8.2$ vs $42.1 \pm 7.3 \mathrm{~g}$, respectively) [1], it would be of interest if the authors had compared the relative pancreas weights of their two subgroups with those of organ donors from the Network for Pancreatic Organ donors with Diabetes (nPOD) programme. This might have allowed for better comparisons between the two studies. From our own examination, four donors of Asian ethnicity exist in the nPOD biobank, of whom 
Table 1 Raw pancreas weights for organ donors or patients over 18 years of age are comparable across two previously reported cohorts

\begin{tabular}{|c|c|c|c|c|c|c|c|}
\hline Study & Group & $n$ & $\begin{array}{l}\text { Age } \\
(\text { mean } \pm \mathrm{SD})\end{array}$ & $\begin{array}{l}\text { Diabetes duration } \\
(\text { mean } \pm \text { SD })\end{array}$ & Duration range & $\begin{array}{l}\text { Pancreas weight } \\
(\text { mean } \pm \text { SD) }\end{array}$ & $\begin{array}{l}\text { Pancreas } \\
\text { weight range }\end{array}$ \\
\hline \multirow[t]{2}{*}{ Campbell-Thompson et al [7] } & T1D & 20 & $31.5 \pm 9.6$ & $18 \pm 10$ & $7.0-14.0$ & $44.9^{\mathrm{a}} \pm 20.4^{\mathrm{b}}$ & $23.4-117.4$ \\
\hline & Non-diabetic control & 23 & $29.0 \pm 8.9$ & - & - & $81.4^{\mathrm{a}} \pm 4.5^{\mathrm{b}}$ & $52.7-139.0$ \\
\hline \multirow[t]{3}{*}{ Kobayashi et al [1] } & LADA & 11 & $64 \pm 14$ & $13 \pm 7$ & $0.3-24.0$ & $29.8 \pm 8.2$ & $18.4-45.0$ \\
\hline & AT1D & 10 & $60 \pm 9$ & $26 \pm 11$ & $13.0-47.0$ & $42.1 \pm 7.3$ & $30.0-59.5$ \\
\hline & Non-diabetic control & 10 & $66 \pm 6$ & - & - & $79.3 \pm 9.3$ & $63.1-95.1$ \\
\hline
\end{tabular}

${ }^{\text {a }}$ Least squares means, as values were age- and BMI-adjusted

${ }^{\mathrm{b}}$ Standard error of the mean

(A)T1D, (Acute) type 1 diabetes

three have pancreas weight data. Two were diagnosed as having type 2 diabetes and were included in the type 2 diabetes donor set in our paper [2] while the third donor was pregnant at the time of death.

We believe it helpful to compare some reported clinical features between the two studies. Significant differences appear for age between the nPOD organ donors with type 1 diabetes and the patients reported in the Kobayashi et al letter (32.2 \pm 16.2 vs $60 \pm 9$ years, respectively) [1, 2]. In our recent Diabetologia paper [2], donors ranged from neonates to 59 years of age, thus making raw pancreas weights impossible to compare. Using raw pancreas weights from nPOD organ donors older than 18 years of age [7], we find significant overlap between donors with type 1 diabetes (any subtype) and those without diabetes in both studies (Table 1). This is critical to the argument by Kobayashi et al relating to the mixing of type 1 diabetes subgroups in our paper [2]. In a previous paper reporting ductular lesions studied by endoscopic retrograde pancreatography [8], the authors used different definitions: insulin-dependent diabetes mellitus (IDDM), islet cell antibody (ICA)-positive non-insulindependent diabetes mellitus (NIDDM), and ICA-negative NIDDM. The latter were unlikely to have clinical type 1 diabetes given their lack of insulin dependence.

Another comment by Kobayashi et al related to pancreases with reduced weights having lobular differences $[9,10]$. It is unclear what issues are under dispute, according to these authors, as both referenced papers provided clear examples of lobular heterogeneity in $\mathrm{CD}^{+}$cell infiltration and HLA MHC Class I hyperexpression, respectively. Furthermore, lobular heterogeneity has been extensively reported in type 1 diabetes for residual beta cells and insulitis (for example [11-13]).

The ductal epithelial hyperplasia/dysplasia (DEHD) lesion shown in Fig. 1 of the Kobayashi et al letter may be termed pancreatic intraepithelial neoplasia (PanIN) by others, with the classification of the lesion as PanIN-1 [14]. As noted by the authors, such lesions are common in aged pancreases, particularly in those with obesity and fatty pancreatic infiltration; although the actual incidences are dependent on the number of blocks and pancreas regions examined [15]. These lesions are also found in pancreases with pancreatic neuroendocrine adenomas, as previously published in a subset of the nPOD donor population with type 2 diabetes [16]; these type 2 diabetic donors were included in the paper on relative pancreas weights [2].

We would also like to take this opportunity to respond to a letter from Dr Saisho regarding our study [17]. We are thankful for his review as we are aware of his paper on pancreas weights and volumes [18]. Dr Saisho and colleagues report observing proportional increases in pancreas volume as determined by computerised tomography (CT) in both the pancreatic parenchyma and fat components during childhood but that the fat/parenchyma ratio increased in adulthood. Moreover, their study found that pancreas volume decreased after age $\sim 60$ years. The excellent and agreed-upon points are made that the volume of pancreas components may be different between childhood and adulthood and that our control donors did not include those over 60 years of age. We also agree that our study examined pancreas weight without division of fat and parenchyma compartments. While the weight of parenchyma, considered similar to muscle, would be expected to be the same as for fat, we would expect parenchyma to occupy a smaller volume compared with fat. Further studies would clearly be of interest to many. Finally, we would note that many patients with type 2 diabetes are insulin independent at diagnosis, and the final statement regarding individuals with type 2 diabetes references an article stating that those in the upper tertile of impaired glucose tolerance have lost $>80 \%$ of their beta cell function [19].

Acknowledgements The authors would like to acknowledge the nPOD staff members and organ procurement organisations partnered with nPOD for the recovery of organ donors. Additional donor details can be obtained through the JDRF nPOD website (www.jdrfnpod.org). Donor datasets are available through nPOD DataShare, an online database for collaborative communication organised around the nPOD specimen repository.

Funding This work was supported by the JDRF (25-2013-268, 172012-3 and 25-2012-516 [MC-T, MAA, DAS, JSK]) and NIDDK (1DP3DK101120-01 [MC-T, MAA, DAS]). 
Duality of interest The authors declare that there is no duality of interest associated with this manuscript.

Contribution statement All authors were responsible for drafting the manuscript and revising it critically for important intellectual content. All authors approved the version to be published.

\section{References}

1. Kobayashi T, Aida K, Fukui T et al (2016) Pancreatic ductal hyperplasia/dysplasia with obstructive chronic pancreatitis: an association with reduced pancreatic weight in type 1 diabetes. Diabetologia. doi:10.1007/s00125-016-3867-x

2. Campbell-Thompson ML, Kaddis JS, Wasserfall C et al (2016) The influence of type 1 diabetes on pancreatic weight. Diabetologia 59: 217-221

3. Alberti KG, Zimmet PZ (1998) Definition, diagnosis and classification of diabetes mellitus and its complications. Part 1: Diagnosis and classification of diabetes mellitus provisional report of a WHO consultation. Diabet Med 15:539-553

4. Atkinson MA, Eisenbarth GS, Michels AW (2014) Type 1 diabetes. Lancet 383:69-82

5. Tuomi T, Santoro N, Caprio S, Cai M, Weng J, Groop L (2014) The many faces of diabetes: a disease with increasing heterogeneity. Lancet 383:1084-1094

6. Campbell-Thompson M, Wasserfall C, Kaddis J et al (2012) Network for Pancreatic Organ Donors with Diabetes (nPOD): developing a tissue biobank for type 1 diabetes. Diabetes Metab Res Rev 28:608-617

7. Campbell-Thompson M, Wasserfall C, Montgomery EL, Atkinson MA, Kaddis JS (2012) Pancreas organ weight in individuals with disease-associated autoantibodies at risk for type 1 diabetes. JAMA 308:2337-2339

8. Nakanishi K, Kobayashi T, Miyashita H et al (1994) Exocrine pancreatic ductograms in insulin-dependent diabetes mellitus. Am J Gastroenterol 89:762-766
9. Rodriguez-Calvo T, Suwandi JS, Amirian N et al (2015) Heterogeneity and lobularity of pancreatic pathology in type $1 \mathrm{di}-$ abetes during the prediabetic phase. J Histochem Cytochem 63: 626-636

10. Rodriguez-Calvo T, Ekwall O, Amirian N, Zapardiel-Gonzalo J, von Herrath MG (2014) Increased immune cell infiltration of the exocrine pancreas: a possible contribution to the pathogenesis of type 1 diabetes. Diabetes 63:3880-3890

11. Foulis AK, Stewart JA (1984) The pancreas in recent-onset type 1 (insulin-dependent) diabetes mellitus: insulin content of islets, insulitis and associated changes in the exocrine acinar tissue. Diabetologia 26:456-461

12. Lernmark A, Klöppel G, Stenger D et al (1995) Heterogeneity of islet pathology in two infants with recent onset diabetes mellitus. Virchows Arch 425:631-640

13. Gianani R, Campbell-Thompson M, Sarkar SA et al (2010) Dimorphic histopathology of long-standing childhood-onset diabetes. Diabetologia 53:690-698

14. Hruban RH, Adsay NV, Albores-Saavedra J et al (2001) Pancreatic intraepithelial neoplasia: a new nomenclature and classification system for pancreatic duct lesions. Am J Surg Pathol 25:579-586

15. Rebours V, Gaujoux S, d'Assignies G et al (2015) Obesity and fatty pancreatic infiltration are risk factors for pancreatic precancerous lesions (PanIN). Clin Cancer Res 21:3522-3528

16. Butler AE, Campbell-Thompson M, Gurlo T, Dawson DW, Atkinson M, Butler PC (2013) Marked expansion of exocrine and endocrine pancreas with incretin therapy in humans with increased exocrine pancreas dysplasia and the potential for glucagon-producing neuroendocrine tumors. Diabetes 62:2595-604

17. Saisho Y (2016) The pancreas in humans with and without diabetes. Diabetologia. doi:10.1007/s00125-016-3881-z

18. Saisho Y, Butler AE, Meier JJ et al (2007) Pancreas volumes in humans from birth to age one hundred taking into account sex, obesity, and presence of type-2 diabetes. Clin Anat 20: 933-942

19. DeFronzo RA, Eldor R, Abdul-Ghani M (2013) Pathophysiologic approach to therapy in patients with newly diagnosed type 2 diabetes. Diabetes Care 36(Suppl 2):S127-S138 